\title{
Network analysis of temporal functionalities of the gut induced by perturbations in new-born piglets
}

\author{
Nirupama Benis ${ }^{1}$ (D), Dirkjan Schokker², Maria Suarez-Diez ${ }^{3}$, Vitor AP Martins dos Santos ${ }^{3,4}$, Hauke Smidt ${ }^{5}$ \\ and Mari A Smits ${ }^{1,2,6^{*}}$
}

\begin{abstract}
Background: Evidence is accumulating that perturbation of early life microbial colonization of the gut induces long-lasting adverse health effects in individuals. Understanding the mechanisms behind these effects will facilitate modulation of intestinal health. The objective of this study was to identify biological processes involved in these long lasting effects and the (molecular) factors that regulate them. We used an antibiotic and the same antibiotic in combination with stress on piglets as an early life perturbation. Then we used host gene expression data from the gut (jejunum) tissue and community-scale analysis of gut microbiota from the same location of the gut, at three different time-points to gauge the reaction to the perturbation. We analysed the data by a new combination of existing tools. First, we analysed the data in two dimensions, treatment and time, with quadratic regression analysis. Then we applied network-based data integration approaches to find correlations between host gene expression and the resident microbial species.

Results: The use of a new combination of data analysis tools allowed us to identify significant long-lasting differences in jejunal gene expression patterns resulting from the early life perturbations. In addition, we were able to identify potential key gene regulators (hubs) for these long-lasting effects. Furthermore, data integration also showed that there are a handful of bacterial groups that were associated with temporal changes in gene expression.

Conclusion: The applied systems-biology approach allowed us to take the first steps in unravelling biological processes involved in long lasting effects in the gut due to early life perturbations. The observed data are consistent with the hypothesis that these long lasting effects are due to differences in the programming of the gut immune system as induced by the temporary early life changes in the composition and/or diversity of microbiota in the gut.
\end{abstract}

Keywords: Gene expression, Microbiota, Data-integration, Long-term effects, Early life perturbations, Antibiotic, Stress, Pig intestine

\section{Background}

Evidence is accumulating that perturbations of the early life colonization of the gastro-intestinal (GI) tract by microbes induce long-lasting health effects in individuals $[1,2]$. Though these effects have been studied and documented, the system components involved in the

\footnotetext{
* Correspondence: mari.smits@wur.nl

${ }^{1}$ Host Microbe Interactomics, Wageningen University, Wageningen, The Netherlands

${ }^{2}$ Wageningen UR Livestock Research, Wageningen University, Wageningen, The Netherlands

Full list of author information is available at the end of the article
}

induction and maintenance of such long-lasting effects have not yet been studied in detail. This is because the GI tract itself is a complex and dynamic system with variable interactions between the host tissue, resident microbiota and nutritional factors. The host tissue is comprised of different cells with different functions, varying from the digestion and uptake of nutrients to providing resistance towards toxic components in the diet. The mucosal layer of the GI tract separates the lumen of the digestive tract from the rest of the body and contains the largest repertoire of immune cells that

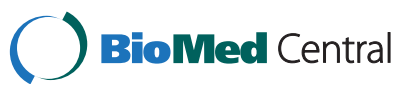


display a pleiotropy of immune signalling and response functions. In addition, the mucosal layer also generates endocrine responses to the lumen of the gut and to the rest of the body. The lumen of the GI tract harbours a complex ecosystem of a huge number and a large variety of micro-organisms, collectively called "microbiota" [3].

Gut microbiota play an important role in modulating diverse gastrointestinal functions, ranging from enzymatic digestion to modulation of immune responses [4-10]. In turn, the host immune system has a regulatory effect on the composition and diversity of the microbiota [11], by mechanisms known as immune exclusion [12]. Early life colonization of the gut with microbiota is an important driver for the development and ultimate functionality of the GI tract in mammalians $[8,13,14]$. Long-lasting effects on the host due to disruption of early life colonisation of the gut have been demonstrated on the level of disease susceptibility, immune parameters [15] and the composition and diversity of microbiota [16]. Early life environmental factors, such as caesarean delivery [17], breastfeeding [18-20], exposure to stress [21, 22], and the use of antibiotics $[23,24]$ influence the microbial colonisation of the gut and affect the development and programming of the mucosal and systemic immune system $[16,25]$. Such early life factors may also result in variation of the abilities of the microbiota to ferment carbohydrates into short-chain fatty acids [26] and/or to ferment indigestible proteins in later stages of life.

The effect of the use of antibiotics on the physiology of the host is believed to be due to the primary effect of antibiotics on the loss/change in bacterial (sub)-populations, especially in the GI tract [27]. The spectrum of the antibiotic and its mode of action determines the effects it has on the gut microbial community [27]. Some reports in this area also suggests that antibiotics have a direct effect on the immune system of the host [27, 28]. For young piglets it has recently been demonstrated that an antibiotic treatment at day 4 after birth causes changes in microbial populations and in tissue gene expression patterns in the small intestine [29,30]. Stress is another factor that can influence the functionality of the GI tract by a temporary secretion of hormones. Such short term hormonal secretions may cause several long lasting effects on the GI immune system [31-33] and on microbiota composition [34]. This has led to studies focusing on the brain-gut-enteric microbiota axis [35-37]. The effect of stress on the GI tissue is most obvious in changes of morphology and functions of the gut [38-40].

The first objective of this study was to develop a workflow that can be used to analyse biological data in two dimensions simultaneously, over time and between treatments. The second objective was to apply this workflow on two types of gut-related data as measured in an experiment with pigs exposed to an early life perturbation, followed by effect measurements at three different timepoints later in life. Using these methods we endeavour to identify gut system components that contribute to induction and maintenance of long lasting effects of early life perturbations. We aim to find major host- and microbe-related components that propagate or regulate these long term effects. Such components may form potential targets to modulate early life events that affect later life immunologic performance. We used piglets as a model and the exposure to an antibiotic and/or stress on day four after birth as the perturbations. We measured whole genome gene expression profiles of intestinal tissues and provided community scale data on the composition and diversity of microbiota on three different time-points, taken during different stages of the lifespan of pigs, neonate, adolescent and full grown adult. In order to take into account the extreme changes in the physiology and morphology of the animal, we simultaneously studied the effect of the treatment and the time. Once the gene expression and microbiota data were analysed separately, we integrated both to obtain information on their possible interactions.

\section{Methods}

\section{Experimental design}

The animal experiment consisted of one control group and two treatment groups, each consisting of 48 piglets derived from 16 different sows (TOPIGS20 $(G Y \times N L)$ ). Each litter contained 4 piglets of each treatment and control group. Litter-mates stayed with their sow until weaning at day 25. After weaning, the same number of piglets of each treatment and control group were housed together in pens. All pens were located in the same compartment. The first treatment group $(\operatorname{Tr} 1)$ was given a dose of Tulathromycin $(0.1 \mathrm{ml}, 2.5 \mathrm{mg} / \mathrm{kg}$ body weight $)$ on the $4^{\text {th }}$ day after birth and then left undisturbed until the time of tissue sampling after sacrifice. The same dose of the antibiotic was given to the second treatment group (Tr2) on the $4^{\text {th }}$ day after birth but these piglets were also subjected to stressful conditions on the same day. The stress was in the form of handling of the piglets, which is common practice in intensive pig husbandry systems (eg, weighing, nail clipping). The control group (Ctrl) was not disturbed for the entirety of the experiment until the time of sacrifice for sampling.

Sampling was done on three time-points, day 8 after they were born, day 55 and day 176. On each of these days, 16 piglets from each treatment group and derived from 16 different sows were sacrificed and samples were collected for microarray and microbiota analysis. Further details of the experiment have been described elsewhere [29]. The experiment was approved by the institutional animal experiment committee "Dier Experimenten Commissie (DEC) Lelystad" (2011077.b), in accordance with 
the Dutch regulations on animal experiments. Additional file 1: Figure S1 gives an overview of the experimental design.

\section{Sample preparation and data generation}

For transcriptome analysis, jejunal tissues scrapings were taken and RNA was extracted from the samples for microarray analysis as described in [29]. For microbiota analysis luminal contents were taken from the same location of the jejunum as the tissue scrapings and microbial DNA was extracted. The microbial composition was detected by the Pig Intestinal Tract Chip (PITChip) [41] version 2.0. The PITChip is a phylogenetic microarray with 3299 oligonucleotides based on 16S rRNA gene sequences of 781 porcine intestinal microbial phylotypes $[42,43]$. The protocol for hybridization and generation of data was performed essentially as described before $[29,44]$. More details on sample preparation is given in previous descriptions of this experiment [29] and the data is available in GEO [45] with the accession number GSE53170 [46].

\section{Gene expression analysis Microarray normalization and quality control}

Background correction and quantile normalisation was performed on the microarray data (GSE53170) using the $\mathrm{R}$ package LIMMA [47] from Bioconductor [48]. After quality control, six microarray samples were removed from the original 72 samples and all further analysis were done on the remaining 66 microarray samples. Data points below the $5^{\text {th }}$ percentile of intensities were removed, this resulted in 25,915 genes from 66 microarray samples. Details of the applied analysis pipeline are given in Additional file 2: Figure S2.

\section{Identification of differences in gene expression profiles}

To identify genes with significant expression profile differences over time between the experimental groups, we used maSigPro [49] from Bioconductor. The time profile (expression over the three time-points) from each treatment was compared to that of the control. Quadratic regression was used to retrieve genes with time profiles significantly different for the treatments versus the control group. The calculations were done with the default settings of the function maSigPro. With three timepoints there are three regression coefficients calculated for each gene's expression profile. At least one of these coefficients has to be significant (with FDR corrected $\mathrm{p}$-values less than 0.05) for the gene to be included in the result. The first coefficient ( $\beta 1)$ denotes the difference in the first time point (day 8 ) between one treatment group and the control. The second one ( $\beta 2$ ) indicates the difference in slope between the first two time points. The third coefficient $(\beta 3)$ shows difference in curvature of the expression patterns and can thus capture long term differences between treatment and control expression patterns of the same gene. Each treatment is compared against the control group and this gives two lists, Tr1vsCtrl (Antibiotic vs Control) and Tr2vsCtrl (Antibiotic + Stress vs Control). For the rest of the analysis three lists of genes were used; genes unique to Tr1vsCtrl (OnlyTr1); gene unique to Tr2vsCtrl (OnlyTr2) and the overlapping genes $(\operatorname{Tr} 1 \& \operatorname{Tr} 2)$.

GO (Gene Ontology) enrichment analysis [50], with focus on the sub-ontology Biological Process, was performed using the R package topGO [51]. The Fisher test was applied to obtain significantly enriched GO terms, only the terms with p-values below 0.01 were included.

\section{Functional interaction networks}

Functional interaction networks among groups of genes selected from the data, were built using the Cytoscape [52] Reactome FI (Functional Interaction) application [53-55] and visualised with the organic layout. The network was built from information in the Reactome FI database such that nodes are genes and edges are interactions, either known or predicted. Modules in the networks were identified using community structure detection as described in [56]. Using inbuilt functions in the Reactome FI app, GO enrichment analysis was performed on each of the identified modules. The final networks consisted of modules with more than 5 nodes and with significantly enriched GO terms. The topological features of these final networks were determined using the NetworkAnalyzer [57] tool in Cytoscape. Hubs were defined to be the nodes in the top $40 \%$ of the degree distribution, where the degree is the number of connections of each node. These hubs were analysed using information from www.genecards.org.

\section{Analysis of microbiota}

Microbial populations from the jejunum were analysed using the PITChip.2 [41], which provides information on three levels of taxonomic resolution, level 1 is similar to the phylogenetic family, level 2 corresponds mostly to the genus level and level 3 is more the species level. Level 2 data provided population percentages for 151 microbial genus groups. Initial exploratory analysis was done on the microbial data with the $\mathrm{R}$ package microbiome (http://microbiome.github.io/) and the MySQL database as described by Rajilic-Stojanovic [44]. Microbial groups that do not differ between control and treatment piglets were filtered out with a threshold of 0.01. A twoway ANOVA analysis of the temporal patterns with the package maSigPro was used to obtain only the groups that change with treatment or time, with a statistical significance threshold of 0.05 . 


\section{Integration of gene expression and microbiota data}

The mixOmics $\mathrm{R}$ package $[58,59]$ was used to integrate gene expression and microbiota abundance data and to perform regression analysis of these two data types. The genes used were those selected using the method described in section Gene expression analysis, which leads to the identification of genes whose temporal expression profiles were significantly different between the control vs. the treatment group. The bacterial groups used for integration were also different either across time or between treatments. We set the microbial information as the independent variable and the gene expression data as the dependent variable. Interchanging the two set of parameters did not affect the results significantly. We only used the significant genes from the gene expression analysis as input for the data integration. Subsequently three networks were built using sparse Partial Least Squares for each of the gene lists OnlyTr1, OnlyTr2 and Tr1\&Tr2. The first two networks were based on six variables (treatment and control in three time-points) and the third one on nine variables (two treatments and the control in three time-points).

The resulting un-directed network connects the microbial groups and the genes that have absolute correlation values above 0.8 . A positive high edge weight hints to a positive regulatory relationship while a low (negative) weight indicates a possible repression relationship. Networks were visualised using Cytoscape 3.1.0. Enrichment analysis was done on the gene neighbours of the bacterial groups via topGO. Fisher's test was applied on the results and only terms with $\mathrm{p}$-values lesser than 0.01 were further analysed. The functionality of the bacterial groups was determined with the help of experts in the field.

\section{Results}

\section{Genes, gene networks and hubs}

For gene expression analysis, the temporal profiles of the samples from each treatment group were compared with those of the control group. We used quadratic regression analysis to obtain two gene lists: one for Tr1vsCtrl (1643 genes) and another one for Tr2vsCtrl (1562 genes). These lists are in Additional file 3. The genes in these lists show significant differences in their gene expression profiles over time between the control and treatment groups. Additional file 4: Figure S4 shows the temporal expression profiles of some genes, showcasing different possible behaviours under different conditions. For example, the expression profiles over time of CHIT1 differs for all three conditions while the profiles of some other genes, such as GRB2 and MAPK14, show most difference in only one treatment compared to the Ctrl. In other cases, such as ERBB4, MX2 and RELA, significant differences in expression are restricted to a single time point. Based on the $\beta 3$ coefficients (explained in the Methods section Gene expression analysis), $60 \%$ of the OnlyTr1 and OnlyTr2 gene-lists have genes with long lasting differences between the treatment and control. The Tr1\&Tr2 list has $91 \%$ of the genes that have significant long term differences. The three gene lists; OnlyTr1, Tr1\&Tr2 and OnlyTr2 consist of genes that have gene expression profiles over time that are significantly different in the treatment compared to the control group. These lists are used for the follow-up of the analyses. On these three lists, functional analysis was done using GO enrichment analysis for biological processes with topGO. A summary of the results is presented in Fig. 1.

In order to verify the results of the topGO analysis and to get insight into networks of genes potentially involved in the induction and maintenance of the longlasting effects, a network based analysis was used. The Reactome Functional Interaction (FI) database was used to build three functional interaction networks, one for each list of genes. In any of the explored gene sets, about $30 \%$ of the genes were represented in the FI networks. More than $50 \%$ of the nodes had significant long-term differences from the control, with the Tr1\&Tr2 FI network having the biggest fraction (94\%). Within each of the FI networks, we were able to identify several topological modules. We identified 9 modules with significant biological function in the OnlyTr1 network, 10 modules in the Tr1\&Tr2 network, and 6 modules in the OnlyTr2 network. The modules are depicted by different colours in Fig. 2. Subsequently GO enrichment analysis for Biological Processes was performed on the genes in each of the identified modules. The GO terms

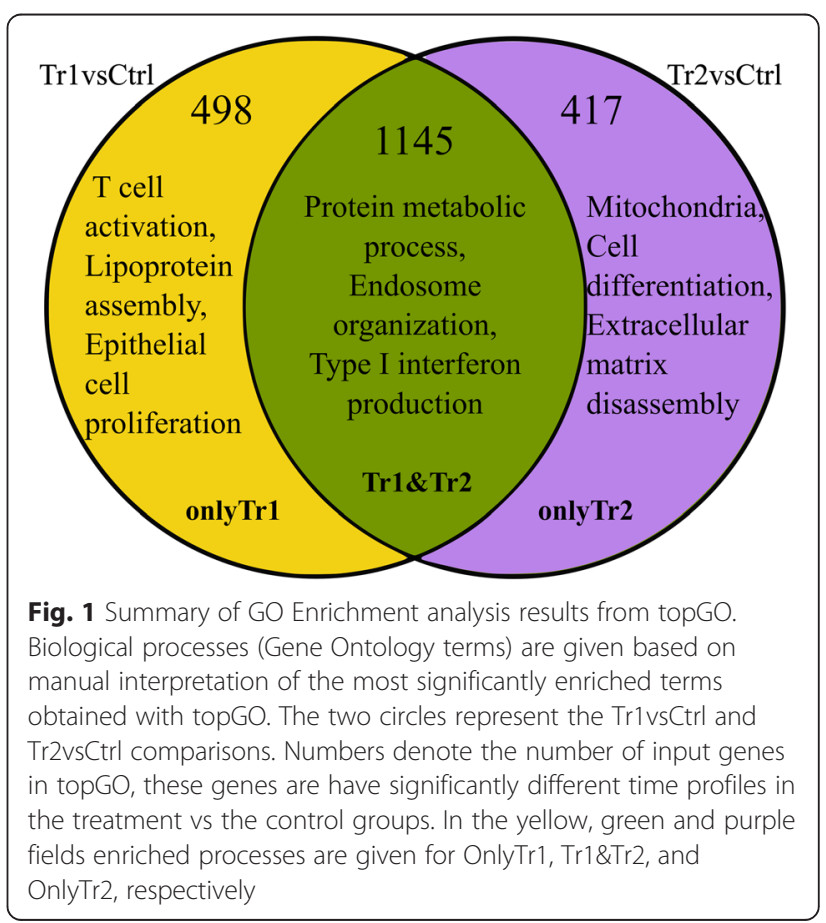




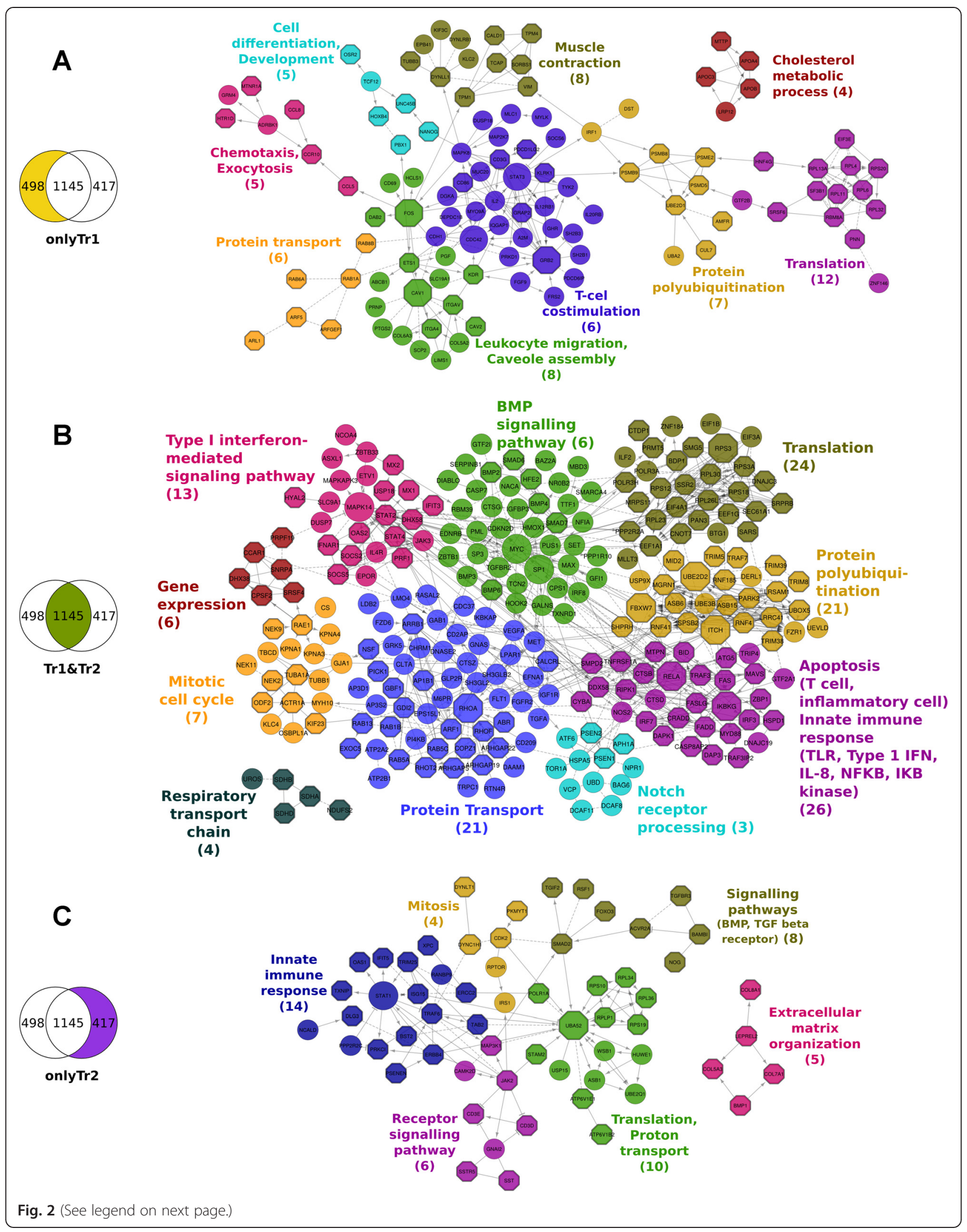


(See figure on previous page.)

Fig. 2 Functional Interaction networks $(\mathbf{a}, \mathbf{b}, \mathbf{c})$. Genes are represented as nodes in the networks, all these genes have time profiles that are significantly different in the treatment than in the control. The edges represent interactions between genes as determined by Reactome. Arrows represent directed interactions, bar-headed arrows indicate inhibition reactions. Dotted lines indicate predicted relationships. Network A was built from OnlyTr1 genes, network B from the common or overlapping genes (Tr1\&Tr2) and network C from OnlyTr2 genes. Colours in the network represent the network segmentation into modules. The text denotes the $\mathrm{GO}$ term that was most enriched for the genes in that module and the number in brackets denotes the number of genes associated with that particular $\mathrm{GO}$ term. Octagonal nodes are related to the $\mathrm{GO}$ term at the set p-value threshold. The nodes with a larger diameter are hubs in the networks. High resolution images of the individual networks are given as Additional file 5: Figure S5, Additional file 6: Figure S6 and Additional file 7: Figure S7. The nodes of the Tr1\&Tr2 network were rearranged for better visualisation of the modules; the network in the original structure is in Additional file 8: Fig. 4 Additional file 9: Fig. 5

with the highest enrichment score for each module are shown in Fig. 2. The results of GO enrichment by both methods for the same gene lists are notably different especially in the OnlyTr2 list. Information on the various topological parameters of the three networks can be found in the Additional file 10.

The results from topGO show that the OnlyTr1 and Tr1\&Tr2 genes are mainly involved in innate and adaptive immune processes, whereas the OnlyTr2 list is dominated by genes involved in developmental processes. Compared to the topGO analysis, the enrichment analysis from Reactome FI provided more detailed functional information. It showed that the genes in all three lists are involved in immune processes with dominance of adaptive immune processes in OnlyTr1 and innate immune processes in OnlyTr2. The overlapping gene list Tr1\&Tr2 included immune signalling functions, interferon and interleukin genes, that are speculated to contribute to both types of immunity [60-62].

The network analysis provided insight into genes with potential high level regulatory activity, i.e. genes in the network with high number of connections/edges. A list of these potential high level regulators or hubs and a gist of their known biological functions is given in Table 1. The temporal expression patterns of three of these 17 genes are shown in Fig. 3 (all 17 of them can be found in the Additional file 11: Figure S11). Except for the two hubs of the OnlyTr1 FI network, all the hubs have long term differences in expression between the treatment and control based on the $\beta 3$ regression coefficient. The hubs in all the three networks can be roughly assigned to three functional categories: immune, cell cycle or proliferation, and genes involved in ubiquitination. There are two genes that are not part of these three clusters, MAPK14 and RPS3, where the latter is an important component of the ribosome. MAP kinases act as an integration point for multiple biochemical signals, involved in a wide variety of cellular processes like proliferation, differentiation and development. They are activated by environmental stresses or cytokines.

All the hubs in the OnlyTr1 are either immune or cell cycle/proliferation related genes. This is reflected in the positioning of these genes in the network. They are found in the two modules related to immunity; T-cell co-stimulation and leukocyte migration (Fig. 2). The genes in the ubiquitin cluster are from the Tr1\&Tr2 and OnlyTr2 networks; they code for ubiquitin itself (UBA52) and also for proteins that perform the conjugation and ligation of ubiquitin to other proteins. These hubs in the $\operatorname{Tr} 1 \& \operatorname{Tr} 2$ network are in the module for protein ubiquitination; this module has the highest number of hubs. Other hubs in this network are from four

\section{STAT3}

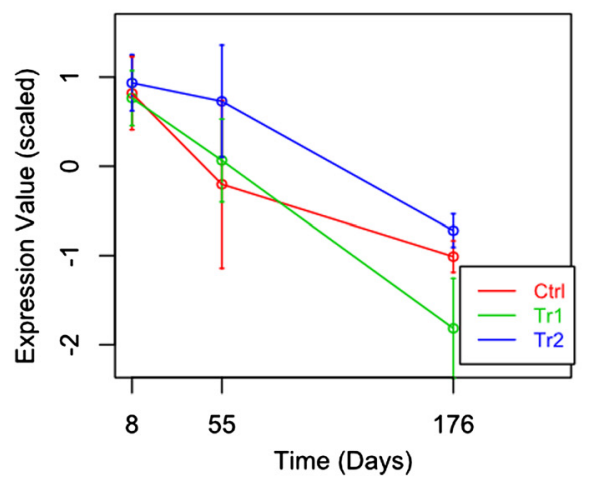

STAT1

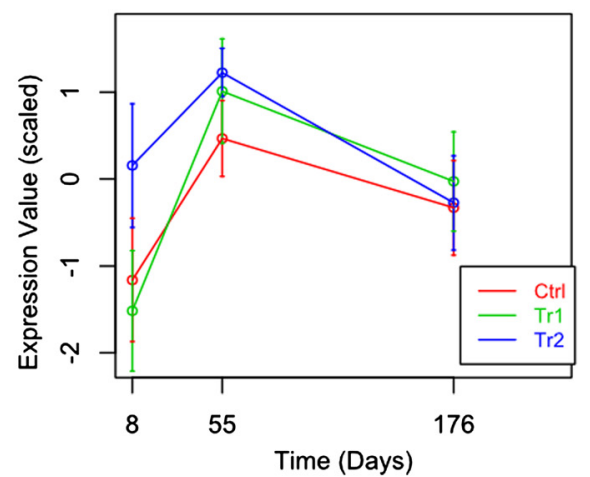

Fig. 3 Gene expression patterns of important hubs. In Fig. 3 each graph depicts the temporal expression pattern of a single gene. These temporal changes are shown under three different conditions: Ctrl (red line), Tr1 (green line), and Tr2 (blue line). The x-axis indicates the time in days. The expression values ( $y$-axis) are scaled such that the average expression of each gene is 0 and the standard deviation is 1 
modules as shown in Fig. 2. In the OnlyTr2 network, there are two hubs, UBA52 and STAT1.

\section{Microbiota temporal changes}

The relative contribution of the microbiota was filtered as described in Methods and was left with 125 microbial groups which represent $99 \%$ of the population. The relative contribution values of these 125 groups were used in the regression analysis to identify groups that can be further related to gene expression levels. After a two-way ANOVA analysis in maSigPro, there were 46 microbial groups that showed significant differences over time or treatment compared to the control. Some bacterial groups like Brachyspira show different contributions in different conditions but some groups like Bacillus et rel show major differences only at one time point and one treatment. Additional file 12: Figure S12 shows these temporal changes for all the 46 groups.

\section{Integration of microbiota and gene expression analysis}

By performing statistical integration of both the microbiota and host gene expression datasets, (mixOmics $\mathrm{R}$ package), we tracked changes in jejunal gene expression which follow the changes in microbial populations as determined on the same location in the gut. The changes will reflect the similarity or dissimilarity of a pair of data points across time. The resulting similarity matrix was used to connect the microbial groups and the expression of genes into a network. The first network, OnlyTr1, was built with 498 genes in 6 conditions (Ctrl, Tr1 with 3 time-points each) and 46 level 2 microbial groups in the same conditions. The second network (Tr1\&Tr2) was built with 1145 genes and the same 46 microbial groups, and the conditions were the control and both $\operatorname{Tr} 1$ and $\operatorname{Tr} 2$ at the 3 time-points, this gave rise to 9 conditions. The third one had again 6 conditions (Ctrl and Tr2 in 3 time-points) with 417 genes and the same 46 bacterial groups. The networks represent the correlation between the microbiota and the gene expression data and are shown in Fig. 4.

There are a total of 22 bacterial groups involved in the three networks, among these, 7 are found in all three networks (Table 2). Most of these bacterial groups share the same temporal pattern of relative contribution (shown in Additional file 13) and are characterized by an increase in abundance over time. Of the 22 bacterial groups in the three correlation networks, only six are known to be possible pathobionts and their abundance, though increasing with time, remains low at all timepoints and treatments. The other 16 bacterial groups are known for being beneficial to the intestine by producing short chain fatty acids or reducing toxic substances (Table 2). Four of the bacterial groups show a decrease in abundance, and are found in the OnlyTr2 correlation network. Three bacterial groups had consistently large number of gene neighbours: Eubacterium et rel, Faecalibacterium et rel and Ruminococcus bromii. These three groups also share several gene neighbours in all the three networks and are quite central in the network as indicated by network parameters (Additional file 14).

Network topological features also revealed that in all three networks, 40 to $55 \%$ of the host genes were neighbours of a single bacterial group. The rest of the genes highly correlate with more than one bacterial group, and a maximum of 8 bacterial groups. About $60 \%$ of the genes are shared between at least two bacterial groups. The maximum radiality (indicative of how connected the nodes are to all the other nodes, with values ranging from 0 to 1 ) was 0.8 to 0.9 . This is apparent from the visualization of the networks in Fig. 4 which shows only a few nodes in the centre connected to most of the other nodes. In the three correlation networks, $60-80 \%$ of the edges have negative correlation values.

The GO terms that appeared enriched in the gene list of each of the correlation networks are mostly related to four broad functions, metabolic processes, transport of substances, translation, and some immune processes (shown in Additional file 15). Most of these genes are negatively correlated with the bacterial groups; this indicates general reduction of the expression levels of these genes across time. But these genes exhibit significant treatment effects, especially long term effects which are not reflected in the temporal patterns of the bacterial groups with which they are highly correlated.

In each correlation network, $20 \%$ of the genes are found in the FI networks from gene expression data alone. A separate topGO analysis shows that the genes in each of the correlation networks are enriched for GO terms that are related to four broad categories of biological processes. These categories are, Metabolic Process, Transport, Translation and Immune Processes. In the Only $\operatorname{Tr} 1$ and $\operatorname{Tr} 1 \& \operatorname{Tr} 2$ correlation networks, the genes associated with the most significant $\mathrm{GO}$ terms are mostly (70 and $80 \%$ ) negatively correlated with the microbial groups. But in the OnlyTr2 correlation network, these genes are mostly $(60 \%)$ positively correlated with the microbial groups. More than $50 \%$ of the genes in the three networks have significant long term differences from the control.

\section{Discussion}

In this paper we describe a workflow and a set of methods capable of analyzing and integrating different types of data in two dimensions, treatment and time. These methods were then used for the identification of gut system components that contribute to the induction and maintenance of long-lasting effects in the GI tract as induced by perturbations at a young age. To this end 


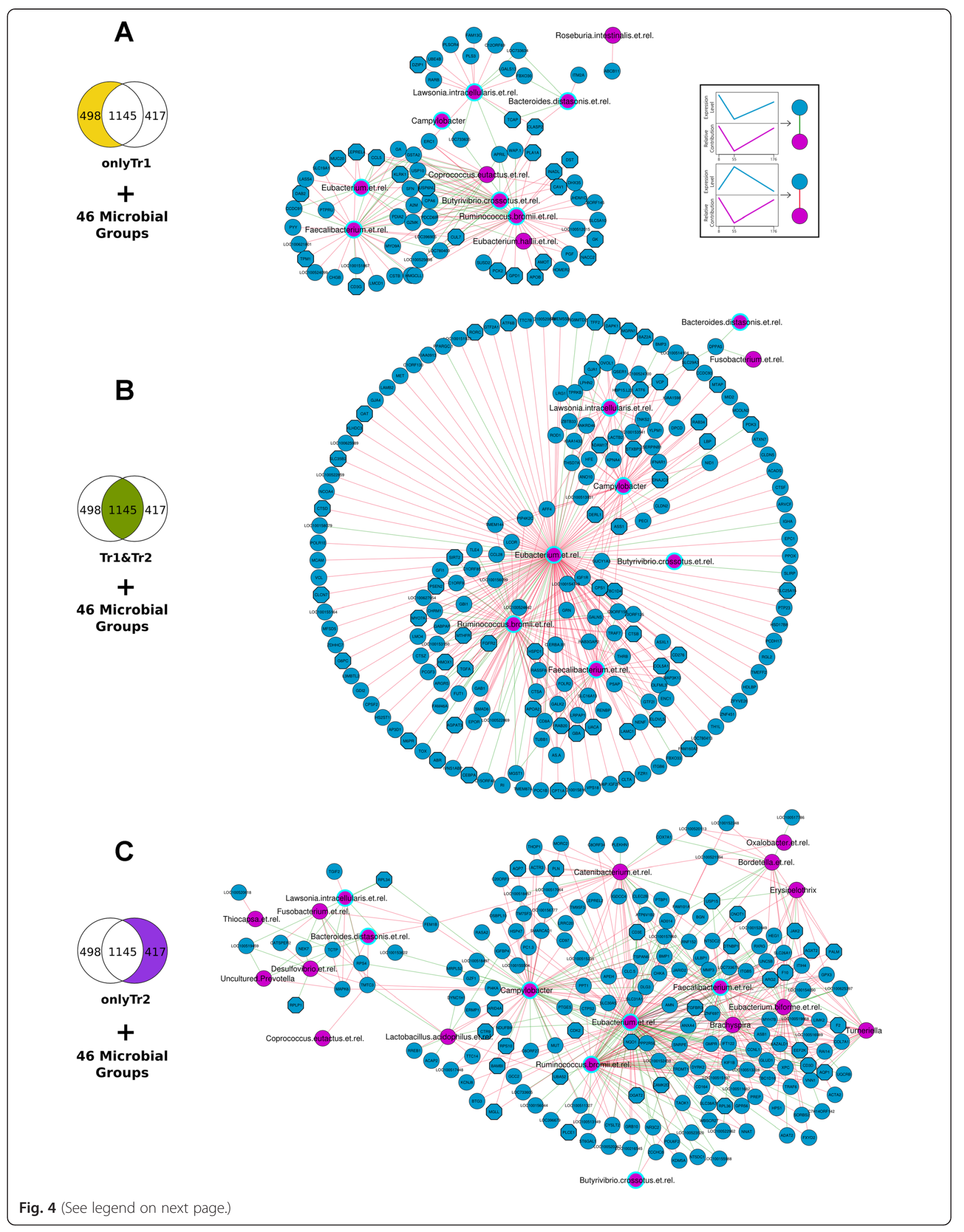


(See figure on previous page.)

Fig. 4 Correlation networks of changes in gene expression patterns and microbiota composition: Blue nodes represent genes and the pink ones represent bacterial groups; pink nodes with a cyan boundary are nodes common in the three networks. The edges represent positive (green) and negative (red) correlation between a gene and a bacterial group. Networks (a), (b) and (c) were built by correlating the gene lists OnlyTr1,

Tr1\&Tr2 and OnlyTr2 respectively with the 46 microbial groups resulting from the regression analysis. All the nodes (bacterial groups and genes) have a significantly different expression profile in time or treatment compared to the control. High resolution images of the individual networks are given as Additional file 10: Figure S10, Additional file 8: Figure S11 and Additional file 12: Figure S12

we combined multiple, freely available tools and advanced statistical analytical tools. We used temporal gene expression patterns, obtained using microarray technology, to identify genes and biological processes that are affected over time by the early life perturbation with antibiotic and/or stress treatments. In addition, we used community-scale analysis of gut microbiota from the same location of the gut to identify changes in microbiota profiles over time due to the perturbations.

With this approach we have taken the first steps in unravelling the genomic and microbial networks that contribute to long-lasting responses of early life perturbations in the gut. The results reveal that there are significant long-lasting differences in the system of the GI tract between the different perturbations groups, mainly at the gene expression level. The data presented are consistent with the hypothesis that observed long lasting effects on gene expression are most probably due to differences in the programming of the gut immune system as induced by the temporary early life changes in the composition and/or diversity of microbiota in the gut. Furthermore, we were able to identify potential key regulator genes (hubs) for the long-lasting effects and we have identified microbial groups that are potentially associated with the observed changes in intestinal gene expression.

In the following sections of this Discussion we explain the rationale behind choosing these methods for our particular biological question. In the sections "Biological relevance of the hubs", "Crosstalk between host and microbe components" and "Understanding the long lasting changes in the host" we examine the biological relevance of the results. The other sections mainly deal with methodology aspects.

\section{Experimental approach}

Intestinal gene expression and microbiota profiles were generated on three different time-points; day 8 (neonatal), 55 (young adult), and 176 (adult). Day 8 was chosen because it is known that immediately after perturbations, as used here, changes occur in the pattern of microbial colonizing of the gut as well as in the GI tract mucosal gene expression [27, 28, 34]. The second measurement at day 55 was chosen because the microbiota would have stabilised by then after weaning (around day 28). Weaning is an extremely turbulent process [63-65] that brings about several temporary changes which are not the focus of our study. The last measurement was on day 176 after birth which coincides with the time of slaughter of these pigs.

Intestinal bacterial composition and gene expression patterns change over the lifetime of an animal due to changes in nutritional, environmental and physiological factors [64, 66, 67]. Obviously, these normal developmental changes could also be detected in this study; however we were particularly interested in deviations from the normal developmental patterns due to the early life perturbations. Previous work on subsets of these data $[29,30]$ showed that there are significant differences between the control and treatment groups at each time point. In the analysis described here, we incorporated the information across time and between treatments by the use of a quadratic regression analysis (maSigPro $\mathrm{R}$ package). In addition, we studied the behaviour of the microbiota over time and looked for correlations with gene expression patterns using the mixOmics $\mathrm{R}$ package, because it is known that the microbiota and gut mucosal tissue respond to each other in various ways $[68,69]$.

Analysis of treatment effect on temporal gene expression For analysis of data derived from three time-points and two treatments, a regression analysis is better suited than a pairwise comparison with linear models, PCOA or hierarchical clustering which was done in earlier work by Schokker et al. [29, 30]. The resulting gene lists from Tr1vsCtrl and Tr2vsCtrl are separated into three lists to be able to look at the biological processes common to both the gene lists which is expected to be due to the effect of the antibiotic. With the resulting three gene lists, we performed GO enrichment analysis with two different methods: topGO and Reactome. An important difference between the two methods is that Reactome is manually curated with experimentally verified information; whereas topGO only uses gene annotation information that is, in many cases, automatically generated without further manual verification. As expected, the Reactome analysis resulted in richer information and encompassed most of the results from the topGO analysis. The network format of Reactome also allows for more informative visualization and further analysis using the topology. For these reasons we decided to 
Table 1 Description of the 17 hubs in the three functional interaction networks

\begin{tabular}{|c|c|c|c|}
\hline & Gene symbol & Function & Summary \\
\hline \multirow[t]{5}{*}{ OnlyTr1 hubs } & GRB2 (17) & $\begin{array}{l}\text { Important link between growth factor receptors on the } \\
\text { cell surface and Ras signalling }\end{array}$ & Cell cycle/ Proliferation \\
\hline & STAT3 (15) & $\begin{array}{l}\text { In response to cytokines and growth factors, STAT family } \\
\text { members are phosphorylated and translocate to the } \\
\text { nucleus to function as transcription factors }\end{array}$ & Immune \\
\hline & CDC42 (12) & $\begin{array}{l}\text { A GTP-ase involved in signalling for several processes, } \\
\text { cell migration, morphology, endocytosis, cell cycle } \\
\text { progression and cell proliferation }\end{array}$ & Cell cycle/ Proliferation \\
\hline & CAV1 (11) & $\begin{array}{l}\text { Encodes a scaffolding protein that is an essential part of } \\
\text { caveolar membranes }\end{array}$ & Immune \\
\hline & FOS (11) & $\begin{array}{l}\text { The FOS family encodes for leucine zipper proteins. } \\
\text { Regulates cell proliferation, differentiation, } \\
\text { transformation and apoptotic cell death }\end{array}$ & Cell cycle/ proliferation \\
\hline \multirow[t]{10}{*}{ Tr1\&Tr2 hubs } & MYC (31) & Transcription factor that activates growth related genes & Cell cycle/ Proliferation \\
\hline & MAPK14 (24) & $\begin{array}{l}\text { Important for the cascades of cellular responses evoked } \\
\text { by extracellular stimuli leading to direct activation of } \\
\text { transcription factors }\end{array}$ & \\
\hline & RELA (24) & $\begin{array}{l}\text { Forms a complex with NFKB transcription factor and } \\
\text { regulates the NFKB pathway }\end{array}$ & Immune \\
\hline & UBE2D2 (24) & $\begin{array}{l}\text { Ubiquitin conjugating enzyme that catalyses covalent } \\
\text { attachment of activated ubiquitin to other ubiquitin } \\
\text { ligases }\end{array}$ & Ubiquitination \\
\hline & ITCH (23) & $\begin{array}{l}\text { Ubiquitin-protein ligase which accepts ubiquitin from } \\
\text { an ubiquitin-conjugating enzyme and then directly } \\
\text { transfers the ubiquitin to targeted substrates }\end{array}$ & Ubiquitination \\
\hline & IKBKG (22) & $\begin{array}{l}\text { Regulatory subunit of the IKK core complex which } \\
\text { phosphorylates inhibitors of NFKB and ultimately the } \\
\text { degradation of the inhibitor }\end{array}$ & Immune \\
\hline & SP1 (22) & $\begin{array}{l}\text { Transcription factor (activator or repressor) that } \\
\text { regulates many cellular processes }\end{array}$ & Cell cycle/ Proliferation \\
\hline & $\mathrm{RHOA}(20)$ & $\begin{array}{l}\text { Regulates signalling from plasma membrane receptors } \\
\text { to the assembly of focal adhesions and actin stress fibers }\end{array}$ & Cell cycle/ Proliferation \\
\hline & RPS3 (20) & $\begin{array}{l}\text { Component of the } 40 \text { S ribosomal subunit, where } \\
\text { translation is initiated }\end{array}$ & \\
\hline & FBXW7 (19) & $\begin{array}{l}\text { Part of the ubiquitin ligase complex (SCF) which } \\
\text { recognizes and binds to phosphorylated targets }\end{array}$ & Ubiquitination \\
\hline \multirow[t]{2}{*}{ OnlyTr2 hubs } & UBA52 (20) & $\begin{array}{l}\text { One of the four genes that code for ubiquitin, and } \\
\text { ribosomal components which are part of the } \\
\text { ribosome } 60 \text { s subunit }\end{array}$ & Ubiquitination \\
\hline & STAT1 (12) & $\begin{array}{l}\text { In response to cytokines and growth factors, STAT } \\
\text { family members are phosphorylated and translocate } \\
\text { to the nucleus to function as transcription factors }\end{array}$ & Immune \\
\hline
\end{tabular}

The number of connections of each gene in their respective network is given in brackets along with the gene symbol. The information about the genes is adapted from www.genecards.org. The hubs can be clustered into three broad groups, given in the last column, based on their functions. All these genes have significantly different time profiles in the treatment compared to the control

concentrate our gene expression analysis on the enrichment results from Reactome where ever possible.

\section{Network analysis}

In the FI networks OnlyTr1 and OnlyTr2, more than half of the nodes have a significant long-lasting expression pattern difference in the treatment versus control. This is significant for most of the nodes in the Tr1\&Tr2 FI network which is representative of the action of antibiotic. This reveals that most of the long lasting effects are due to the antibiotic effect in the treatment. These genes with long lasting differences are spread over all the modules which indicates that all the biological processes in the network (Fig. 2) are different over time. Several of these processes are essential cellular processes and some are immune related. This could lead to situations that the treated animals respond differently to external stimuli compared to control animals. In order to look further into these long lasting differences we analyse the hubs of the network. 
Table 2 Summary of the three correlation networks with information on bacterial groups

\begin{tabular}{|c|c|c|c|c|}
\hline \multirow[t]{2}{*}{ Bacterial groups } & \multicolumn{3}{|c|}{ Number of correlated genes in } & \multirow[t]{2}{*}{ Information } \\
\hline & Only Tr1 & $\operatorname{Tr} 1 \& \operatorname{Tr} 2$ & Only Tr2 & \\
\hline Eubacterium et rel & 14 & 165 & 128 & Anaerobic, Gram positive, broad range of species \\
\hline Ruminococcus bromii et rel & 39 & 65 & 63 & $\begin{array}{l}\text { Anaerobic, Gram positive, keystone species in the gut, } \\
\text { digestion of resistant starch }\end{array}$ \\
\hline Faecalibacterium et rel & 35 & 40 & 43 & $\begin{array}{l}\text { Obligate anaerobe, Gram negative, produces butyrate, } \\
\text { has anti-inflammatory properties }\end{array}$ \\
\hline Campylobacter & 1 & 35 & 62 & $\begin{array}{l}\text { Microaerophilic, Gram negative, known pathogen in } \\
\text { humans }\end{array}$ \\
\hline Lawsonia intracellularis et rel & 15 & 22 & 9 & Gram positive, Porcine intracellular enteropathogen \\
\hline Butyrivibrio crossotus et rel & 22 & 1 & 2 & Anaerobic, Gram positive, butyrate producer \\
\hline Bacteroides distasonis et rel & 5 & 1 & 5 & $\begin{array}{l}\text { Obligate anaerobe, Gram negative, reclassified to } \\
\text { Parabacteroides distasonis, produces acetate and } \\
\text { succinate, possible pathogen }\end{array}$ \\
\hline Fusobacterium et rel & & 1 & 9 & $\begin{array}{l}\text { Anaerobic, Gram negative, generally butyrate } \\
\text { producers, possible pathogen, potent } \\
\text { lipopolysaccharide }\end{array}$ \\
\hline Eubacterium hallii et rel & 3 & & & Anaerobic, uses lactate and produces butyrate \\
\hline Roseburia intestinalis et rel & 1 & & & Anaerobic, Gram positive, butyrate producer \\
\hline Coprococcus entactus et rel & 16 & & 1 & Anaerobic, Gram positive, mostly acetate producer \\
\hline Brachyspira & & & 43 & Anaerobic, Gram negative, some known pathogens \\
\hline Eubacterium biforme et rel & & & 36 & Anaerobic, involved in lipid metabolism \\
\hline Catenibacterium et rel & & & 32 & $\begin{array}{l}\text { Obligate anaerobes, Gram positive, digest simple } \\
\text { sugars }\end{array}$ \\
\hline Turneriella & & & 18 & Obligate anaerobes, Gram negative \\
\hline Bordetella et rel & & & 15 & $\begin{array}{l}\text { Obligate anaerobes, Gram negative, known to cause } \\
\text { respiratory diseases }\end{array}$ \\
\hline Erysipelothrix & & & 11 & $\begin{array}{l}\text { Facultative anaerobes, porcine pathogens for skin } \\
\text { diseases }\end{array}$ \\
\hline Lactobacillus acidophilus et rel & & & 10 & $\begin{array}{l}\text { Microaerobic, Gram positive, ferments sugars into } \\
\text { lactic acid, probiotic }\end{array}$ \\
\hline Desulfovibrio et rel & & & 8 & $\begin{array}{l}\text { Aerotolerant, Gram negative, reduce toxic substances } \\
\text { like sulphate }\end{array}$ \\
\hline Uncultured Prevotella & & & 4 & $\begin{array}{l}\text { Gram negative, pathogens in respiratory tract, breaks } \\
\text { down proteins and carbohydrates }\end{array}$ \\
\hline Oxalobacter et rel & & & 2 & Anaerobic, oxalate reducing \\
\hline Thiocapsa et rel & & & 2 & Mostly anaerobic, oxidise sulphur, photosynthetic \\
\hline
\end{tabular}

The bacterial groups that are part of the networks are listed along with the number of genes with which they are highly correlated. Several genes are shared between bacterial groups. Both the genes and the bacterial groups are significantly different either in time or treatment between the control. The first seven groups are common between the three networks. Some general information on these bacterial groups is also given in the last column

\section{Analysis of hubs}

Investigating the hubs of networks gives insight into the entire network function [70] and the nodes in our networks are also found to be important for several biological functions [70-72] as mentioned in the Results. In most network analysis the degree itself [73] or the degree distribution is used to choose the most connected hubs [74]. We chose the top $40 \%$ of the degree distribution as hubs, which is a more lenient threshold than usual because of the large differences in degree distribution within the three networks. Nevertheless, we still were able to identify multiple hubs per network and extract biological functions for these hubs (Table 1). Of the three categories that the functions of the hubs can be classified into, the cell cycle/proliferation category is more abundant than the other two.

It is intriguing to note that most of the hubs of the three networks are known for being high level regulators for several biological processes, which supports the relevance of this network analysis. The hubs from the overlapping network, $\operatorname{Tr} \mathbf{1}$ Tr2 are involved in diverse biological processes and signalling/cascading events. The expression of all the hubs in the OnlyTr1 and the Tr1\&Tr2 networks is significantly different over time in 
comparison with their expression pattern in the control group. We speculate that the treatments directly or indirectly affect these hubs which then regulate genes to bring about the long term effects of the treatments. The hubs in the OnlyTr2 network conspicuously do not have significant expression level differences over the time span of the experiment when compared to the control group. This suggests that the stress component of the treatment does not affect the animal in the long term as much as the antibiotic alone does.

\section{Biological relevance of the hubs}

Among the hubs, there are two STAT genes, STAT3 and STAT1, in the OnlyTr1 and OnlyTr2 networks respectively. The STAT family of genes are well studied and have a role in signalling events but also act as transcription factors [75]. The STAT1, STAT2, STAT3, STAT4 genes, found to have significantly different temporal expression patterns in the treatments versus the control, are especially related to immune reactions [75-77]. This is in agreement with the results of our functional analysis of the networks. STAT3 and STAT1 are known to be upregulated in cases of bacterial infection [75, 78-80]. In addition, expression of STAT1 has been reported to be reduced in the presence of antibiotics [76, 78, 80, 81]. The latter is reflected in our data by the temporal expression patterns shown in Fig. 3. Though the overall expression patterns of STAT1 among the three groups are similar, antibiotic treatment and the concomitant change in microbial communities, has a clear effect on STAT1 expression, especially at the first two time-points. Expression of STAT 1 on day 8 in Tr2 is, however, quite high compared to the Ctrl, this could indicate that the stress applied at day 4 counteracts the effect of the antibiotic. STAT3 is known to be important for survival of embryos [75, 76, 82], it is important during the early stages of development but is not found to be essential in adult tissue [76]. This is reflected in the observed decreasing expression levels of STAT3 over the three time-points (Fig. 3). The observed contrasting expression pattern of the STAT1 and STAT 3 hubs, may be related to the previous observations that STAT1 and STAT3 counteract each other $[80,83]$.

\section{Data integration}

With regard to the microbiota composition and diversity, this study revealed a more prominent effect of time than that of treatment. This is in accordance with previous observations that indicate that the diversity and composition of intestinal microbiota change considerably over time $[84,85]$. As expected, the treatment effects are strongest at the first time point, taking into account the efficacy of the used antibiotic [25, 86]. As soon as the antibiotic wears off, the microbiota returns to the "normal" state. This is consistent with known literature about the resilience of microbial communities $[87,88]$.

Since the gene expression data as well as the microbiota data change with treatment and time, this presents an opportunity to correlate these different types of information and look into probable relationships and interactions in the jejunum between microbiota and gene expression of the cells in the mucosal layer. We assumed that the OnlyTr1 and Tr1\&Tr2 networks represent the effect of the antibiotic on the cross-talk between microbiota and mucosal cells. The OnlyTr2 correlation network could be interpreted as a representation of the cross-talk between the host and microbiota in response to stress, although we did not look at the effect of physical stress alone. The bacterial groups with the most gene connections are common to the three correlation networks. This indicates that the two treatments do not have drastic effects on the possible host microbiota interactions. The OnlyTr2 correlation network has more bacterial groups that correlate with genes which suggests that the physical stress factor alters the cross-talk more than the antibiotic alone does. The number of known pathobionts increases in the latter network which could be an indication of a tendency towards pathology in stressful conditions.

\section{Crosstalk between host and microbe components}

There are three bacterial groups that correlate with a high number of genes in all the three networks: Eubacterium; Ruminococcus bromii; and Faecalibacterium. Eubacterium is a genus with very diverse species. Ruminococcus bromii is a species that has been extensively studied for its ability to breakdown resistant starch [89] to produce acetate on which other bacterial groups can survive. Another beneficial bacterial group is Faecalibacterium which is a relatively new genus with only one species documented so far, F. parusnitzii and it has been reported to be extremely beneficial to the host. Ruminococcus bromii; and Faecalibacterium are reported to be most abundant in the anaerobic environment of the colon $[90,91]$. Nevertheless, there is evidence that the small intestine is populated with quite a few of such fermenters [92]. In our analysis the abundance of these bacterial groups in the jejunum correlates to the expression level of a considerable number of genes. This suggests that they are major players in the crosstalk in the jejunum. Lawsonia intracellularis and species of Campylobacter are found to be correlated with several genes. These groups are known mammalian pathogens of the small intestine. It could be speculated that, in these healthy animals, they are involved in balancing between immune tolerance and immune responses. 


\section{Understanding the long lasting changes in the host}

The results of the regression analysis on gene expression alone show that there are differences between the three treatment groups for a long time after the perturbation. These differences are reflected in immune functions and cell proliferation related functions. It has been suggested that stress and antibiotics compromise the immune system, but in different ways [27, 35, 38]. The action of antibiotics could change the delicately balanced signalling between microbiota and the intestinal cells. This change during early stages of development is expected to influence the development and programming of the immune system with consequences for the later life functioning of the immune system. It has been proposed that macrolides (the type of antibiotic given in this experiment) work by recruiting immune cells to carry the antibiotic to the afflicted tissue [93, 94]. This mode of action will bring about temporary changes in the immune system but cannot explain the observation as described here. Stress is known to cause structural changes in the intestinal tissue [38-40] and may affect the microbial populations [34].

The above described changes are not expected to last over a long period of time; intestinal cells have a large turnover $[95,96]$ almost every 4 to 5 days. Yet we find changes that persist for 51 and even 172 days after the perturbation of the gut system. This suggests that the programming and development of the immune system occurred differently between the different treatment groups. Since the microbial composition at day 8 significantly differed between the treatments groups we believe that the difference in immune programming and development is due to differences in the early life crosstalk in the gut between microbes and host. This line of thinking is agreement with the conclusions in several other recent studies in this area [2,97]. It is also in line with our own observation that the microbiota composition returns to the normal state briefly after the perturbation. Memory cells of the mucosal immune system could play an important role in the programming of the mucosal immune system [30, 67, 98]. Furthermore even though stress was not expected to play a very prominent role in changing the system in the long term, we see that in some instances, it counteracts the effects of the antibiotic. The mechanism behind this is yet to be fully understood.

Pigs are regarded as a useful model for research into modulation of the human gut, especially with regard to microbiota-host immune interactions [99]. This experiment was designed to disturb the pattern of early colonization of the gut by microbiota with known effects later in life [25]. The factors used for perturbation were, treatment with an antibiotic or an antibiotic with stress at day 4 after birth. Both human neonates as well as piglets in intensive husbandry systems may be exposed to such factors. Therefore our results may be relevant for both humans and piglets.

\section{Conclusions}

We used an early life intestinal perturbation in piglets and demonstrate long lasting effects, as measured on the intestinal gene expression level. We provide substantial evidence that several biological processes of the gut mucosal tissue are in a different state between the experimental groups over a long period of time. However, the regression analysis did not identify significant differences among the temporal patterns of the bacterial species, and the treatments do not seem to affect long term changes in the microbiota. We conclude that the difference in immune programming and development is due to differences in the early life crosstalk in the gut between microbes and host, resulting from the perturbations. Since we identified potential high-level regulators of long term changes in the gut, we are one step closer to identifying the underlying mechanisms. Although the treatments did not lead to phenotypical manifestations, like weight differences between the animals, the exposure of pigs to stressors like pathogen challenges could bring out immune variations between the groups. Studying these subtle differences may help to develop strategies to modulate the process of immune development and programming. The results of this paper are supportive for the recent notion that antibiotics should be used more carefully in neonatal humans and animals.

\section{Availability of data}

The data used in this research article is available on Gene Expression Omnibus with the accession number GSE53170, through this link http://www.ncbi.nlm.nih.gov/ geo/query/acc.cgi?acc=GSE53170.

\section{Ethics statement}

The experiment was approved by the institutional animal experiment committee "Dier Experimenten Commissie (DEC) Lelystad" (2011077.b), in accordance with the Dutch regulations on animal experiments.

\section{Additional files}

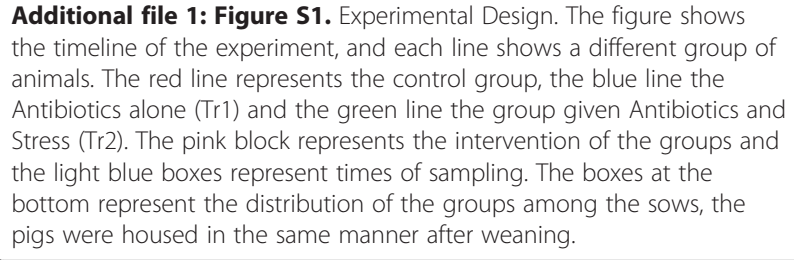




\section{Additional file 2: Figure S2. Microarray Analysis. Workflow of the} microarray analysis with the specific details.

Additional file 3: Figure S3. Types of Differences in Time Profiles. Each graph depicts the temporal expression pattern of a single gene. These temporal changes are shown under three different conditions: Ctrl (red line), $\operatorname{Tr} 1$ (green line), and $\operatorname{Tr} 2$ (blue line). The $x$-axis indicates the time in days, the $y$-axis has expression values scaled such that the average expression of each gene is 0 and the standard deviation is 1 .

Additional file 4: Figure S4. Expression of Fl network hubs. Expression profiles of 17 hubs of the three Fl networks. Each graph depicts the temporal expression pattern of a single gene. These temporal changes are shown under three different conditions: Ctrl (red line), $\operatorname{Tr} 1$ (green line), and $\operatorname{Tr} 2$ (blue line). The $x$-axis indicates the time in days, the $y$-axis has expression values scaled such that the average expression of each gene is 0 and the standard deviation is 1 .

Additional file 5: Figure S5. Original Tr1\&Tr2 Fl network. Network formed with genes that have significantly different time profiles between both treatments vs the control group.

Additional file 6: Figure S6. Temporal changes in composition of bacterial groups used in the correlation networks. Each graph represents the compositional changes of selected bacterial groups over time. The bacterial groups were chosen based on an ANOVA analysis. The time in days is on the $x$-axis, the log values of the contribution of the bacterial groups is on the $y$-axis. Each of the 46 graphs have a different scale on the $y$-axis due to the extreme differences between contributions of each of the bacterial groups.

Additional file 7: Figure S7. Only $\operatorname{Tr} 1$ Reactome Fl network.

Additional file 8: Figure S8. Tr1\&Tr2 Reactome Fl network.

Additional file 9: Figure S9. OnlyTr2 Reactome Fl network.

Additional file 10: Figure S10. OnlyTr1 correlation network.

Additional file 11: Figure S11. Tr1\&Tr2 correlation network.

Additional file 12: Figure S12. OnlyTr2 correlation network.

Additional file 13: List of significant genes in different conditions. Additional file 14: Information on the Reactome FI networks. Additional file 15: Information on the correlation networks.

\section{Abbreviations}

Gl: Gastrointestinal; Tr1: Treatment group 1; Tr2: Treatment group 2: Ctrl: Control group; DEC: Dier experimenten commissie; PITChip: Pig intestinal tract chip; GEO: Gene Expression Omnibus; LIMMA: LInear models for microarray data; maSigPro: Microarray significant profiles; GO: Gene ontology; FI: Functional interactions; MySQL: My structured query language; ANOVA: Analysis of variance.

\section{Competing interests}

The authors declare that they have no competing interests.

\section{Authors' contributions}

NB performed the data analysis and prepared the manuscript. DS performed the experiment and the initial analysis. MSD guided and participated in the data analysis. VMS contributed to the direction of the analysis and the preparation of the manuscript. HS contributed to the analysis of the PITChip data and the final manuscript. MS conceived of the original experiment, directed the analysis and helped drafting the manuscript. All authors read and approved the final manuscript.

\section{Acknowledgements}

The authors would like to acknowledge the fruitful discussions with dr. ir. Henk Parmentier in interpreting the results of the analysis. This work has been financially supported by the Systems Biology Investment Programme of Wageningen University, KB-17-003.02-022.

\section{Author details}

${ }^{1}$ Host Microbe Interactomics, Wageningen University, Wageningen, The Netherlands. ${ }^{2}$ Wageningen UR Livestock Research, Wageningen University, Wageningen, The Netherlands. ${ }^{3}$ Systems and Synthetic biology, Wageningen University, Wageningen, The Netherlands. ${ }^{4}$ Lifeglimmer GmbH, Berlin,
Germany. ${ }^{5}$ Laboratory of Microbiology, Wageningen University, Wageningen, The Netherlands. ${ }^{6}$ Central Veterinary Institute, Wageningen University, Wageningen, The Netherlands.

Received: 26 February 2015 Accepted: 29 June 2015 Published online: 29 July 2015

\section{References}

1. Foliaki S, Pearce N, Björkstén B, Mallol J, Montefort S, von Mutius E. Antibiotic use in infancy and symptoms of asthma, rhinoconjunctivitis, and eczema in children 6 and 7 years old: International Study of Asthma and Allergies in Childhood Phase III. J Allergy Clin Immunol. 2009;124:982-9.

2. Hoskin-Parr L, Teyhan A, Blocker A, Henderson AJW. Antibiotic exposure in the first two years of life and development of asthma and other allergic diseases by 7.5 yr: a dose-dependent relationship. Pediatr Allergy Immunol. 2013;24:762-71.

3. Relman DA. The human microbiome: ecosystem resilience and health. Nutr Rev. 2012;70:52-9.

4. Hooper LV. Bacterial contributions to mammalian gut development. Trends Microbiol. 2004;12(3):129-34.

5. O'Hara AM, Shanahan F. The gut flora as a forgotten organ. EMBO Rep. 2006;7:655-746.

6. Tremaroli V, Backhed F. Functional interactions between the gut microbiota and host metabolism. Nature. 2012:489:242-9.

7. Arrieta M-C, Finlay BB. The commensal microbiota drives immune homeostasis. Front Immunol. 2012;3:33.

8. Kabat AM, Srinivasan N, Maloy KJ. Modulation of immune development and function by intestinal microbiota. Trends Immunol. 2014;35:507-17.

9. Scholtens PAMJ, Oozeer R, Martin R, Ben AK, Knol J. The early settlers: intestinal microbiology in early life. Annu Rev Food Sci Technol. 2012:3:425-47.

10. Ottman N, Smidt H, de Vos WM, Belzer C. The function of our microbiota: who is out there and what do they do? Front Cell Infect Microbiol. 2012;2:104.

11. Willing BP, Gill N, Finlay BB. The role of the immune system in regulating the microbiota. Gut Microbes. 2010;1:213-23.

12. Mantis NJ, Rol N, Corthesy B. Secretory IgA's complex roles in immunity and mucosal homeostasis in the gut. Mucosal Immunol. 2011;4:603-11.

13. Palmer C, Bik EM, DiGiulio DB, Relman DA, Brown PO. Development of the human infant intestinal microbiota. PLoS Biol. 2007;5, e177.

14. Inman CF, Haverson $\mathrm{K}$, Konstantinov SR, Jones PH, Harris C, Smidt H, et al. Rearing environment affects development of the immune system in neonates. Clin Exp Immunol. 2010;160:431-9.

15. Olszak T, An D, Zeissig S, Vera MMP, Richter J, Franke A, et al. Microbial exposure during early life has persistent effects on natural killer T cell function. Science. 2012;336:489-93.

16. Nylund L, Satokari R, Salminen S, de Vos WM. Intestinal microbiota during early life - impact on health and disease. Proc Nutr Soc. 2014;73(4):457-69.

17. Cho CE, Norman M. Cesarean section and development of the immune system in the offspring. Am J Obstet Gynecol. 2013;208:249-54.

18. Weng $\mathrm{M}$, Walker WA. The role of gut microbiota in programming the immune phenotype. J Dev Orig Health Dis. 2013;4:203-14.

19. Kelly D, Coutts AG. Early nutrition and the development of immune function in the neonate. Proc Nutr Soc. 2000;59:177-85.

20. Newburg DS, Walker WA. Protection of the neonate by the innate immune system of developing gut and of human milk. Pediatr Res. 2007;61:2-8.

21. Jarillo-Luna A, Rivera-Aguilar V, Garfias HR, Lara-Padilla E, Kormanovsky A Campos-Rodriguez R. Effect of repeated restraint stress on the levels of intestinal IgA in mice. Psychoneuroendocrinology. 2007;32:681-92.

22. O'Mahony SM, Marchesi JR, Scully P, Codling C, Ceolho A-M, Quigley EMM, et al. Early life stress alters behavior, immunity, and microbiota in rats: implications for irritable bowel syndrome and psychiatric illnesses. Biol Psychiatry. 2009;65:263-7.

23. Schumann A, Nutten S, Donnicola D, Comelli EM, Mansourian R, Cherbut C, et al. Neonatal antibiotic treatment alters gastrointestinal tract developmental gene expression and intestinal barrier transcriptome. Physiol Genomics. 2005;23:235-45.

24. Tanaka S, Kobayashi T, Songjinda P, Tateyama A, Tsubouchi M, Kiyohara C, et al. Influence of antibiotic exposure in the early postnatal period on the development of intestinal microbiota. FEMS Immunol Med Microbiol. 2009;56:80-7. 
25. Arrieta M-C, Stiemsma LT, Amenyogbe N, Brown EM, Finlay B. The intestinal microbiome in early life: health and disease. Front Immunol. 2014;5.

26. Cho I, Yamanishi S, Cox L, Methe BA, Zavadil J, Li K, et al. Antibiotics in early life alter the murine colonic microbiome and adiposity. Nature. 2012;488:621-6.

27. Willing BP, Russell SL, Finlay BB. Shifting the balance: antibiotic effects on host-microbiota mutualism. Nat Rev Microbiol. 2011;9:233-43.

28. Niewold TA. The nonantibiotic anti-inflammatory effect of antimicrobial growth promoters, the real mode of action? A hypothesis. Poult Sci. 2007;86(4):605-9.

29. Schokker D, Zhang J, Zhang L, Vastenhouw SA, Heilig HGHJ, Smidt H, et al. Early-life environmental variation affects intestinal microbiota and immune development in new-born piglets. PLoS One. 2014;9, e100040.

30. Schokker D, Zhang J, Vastenhouw SA, Heilig HG, Smidt H, Rebel JM, et al Long-lasting effects of early-life antibiotic treatment and routine animal handling on gut microbiota composition and immune system in pigs. PLoS One. 2015;10.

31. Jacobson L, Sapolsky R. The role of the hippocampus in feedback regulation of the hypothalamic-pituitary-adrenocortical axis. Endocr Rev. 1991;12(2):118-34.

32. Mayer EA. The neurobiology of stress and gastrointestinal disease. Gut. 2000:47:861-9.

33. Braun T, Challis JR, Newnham JP, Sloboda DM. Early-life glucocorticoid exposure: the hypothalamic-pituitary-adrenal axis, placental function, and long-term disease risk. Endocr Rev. 2013;34:885-916.

34. Collins SM, Bercik P. The relationship between intestinal microbiota and the central nervous system in normal gastrointestinal function and disease. Gastroenterology. 2009;136:2003-14.

35. Konturek PC, Brzozowski T, Konturek SJ. Stress and the gut: pathophysiology, clinical consequences, diagnostic approach and treatment options. J Physiol Pharmacol. 2011;62:591-9.

36. Montiel-Castro AJ, González-Cervantes RM, Bravo-Ruiseco G, Pacheco-López G. The microbiota-gut-brain axis: neurobehavioral correlates, health and sociality. Front Integr Neurosci. 2013;7:70.

37. Mayer EA, Savidge T, Shulman RJ. Brain-gut microbiome interactions and functional bowel disorders. Gastroenterology. 2014;146:1500-12.

38. Söderholm JD, Perdue MH. Stress and the gastrointestinal tract II. Stress and intestinal barrier function. Am J Physiol Gastrointest Liver Physiol. 2001;280:G7-13.

39. Bhatia V, Tandon RK. Stress and the gastrointestinal tract. J Gastroenterol Hepatol. 2005:20:332-9.

40. Taché $Y$, Martinez $V$, Million M, Wang L. Stress and the gastrointestinal tract III. Stress-related alterations of gut motor function: Role of brain corticotropin-releasing factor receptors. Am J Physiol Gastrointest Liver Physiol. 2001;280:G173-7.

41. Pérez Gutiérrez O, van den Bogert B, Derrien M, Koopmans S, Molenaar D, de Vos WM, et al. Design of a high-throughput diagnostic microarray for the characterization of pig gastrointestinal tract microbiota (chapter 3). In: Unraveling piglet gut microbiota Dyn response to Feed Addit [dissertation] Wageningen Wageningen Univ. 2010. p. 40-67.

42. Haenen D, Zhang J, Souza da Silva C, Bosch G, van der Meer IM, van Arkel J, et al. A diet high in resistant starch modulates microbiota composition, SCFA concentrations, and gene expression in pig intestine. J Nutr. 2013:143:274-83.

43. Pérez Gutiérrez O. Unraveling piglet gut microbiota dynamics in response to feed additives. [SI: sn]. 2010.

44. Rajilić-Stojanović M, Heilig HGHJ, Molenaar D, Kajander K, Surakka A, Smidt $\mathrm{H}$, et al. Development and application of the human intestinal tract chip, a phylogenetic microarray: analysis of universally conserved phylotypes in the abundant microbiota of young and elderly adults. Environ Microbiol. 2009:11:1736-51

45. Barrett T, Wilhite SE, Ledoux P, Evangelista C, Kim IF, Tomashevsky M, et al. NCBI GEO: archive for functional genomics data sets - update. Nucleic Acids Res. 2013;41(D1):D991-5

46. Pig experiment Sterksel early antibiotics/stress. [http://www.ncbi.nlm.nih.gov/ geo/query/acc.cgi?acc=GSE53170]

47. Smyth GK. limma: Linear Models for Microarray Data. In: Gentleman R, Carey V, Huber W, Irizarry R, Dudoit S, editors. Bioinformatics and computational biology solutions using R and bioconductor SE - 23, Statistics for Biology and Health. New York: Springer; 2005. p. 397-420.
48. Gentleman R, Carey VJ, Huber W, Irizarry RA, Dudoit S. Bioinformatics and computational biology solutions using $\mathrm{R}$ and bioconductor. Volume 746718470. Springer; 2005.

49. Conesa A, Nueda MJ, Ferrer A, Talón M. maSigPro: a method to identify significantly differential expression profiles in time-course microarray experiments. Bioinformatics. 2006:22:1096-102.

50. Dopazo J. Functional interpretation of microarray experiments. Omi a J Integr Biol. 2006;10:398-410.

51. Alexa A, Rahnenführer J. Gene set enrichment analysis with topGO. 2009

52. Shannon P, Markiel A, Ozier O, Baliga NS, Wang JT, Ramage D, et al. Cytoscape: a software environment for integrated models of biomolecular interaction networks. Genome Res. 2003;13(11):2498-504.

53. Croft D. Building models using reactome pathways as templates. In: Schneider MV, editor. In Silico Systems Biology SE - 14, Methods in Molecular Biology, vol. 1021. New York: Humana Press; 2013. p. 273-83.

54. Milacic M, Haw R, Rothfels K, Wu G, Croft D, Hermjakob H, et al. Annotating cancer variants and anti-cancer therapeutics in reactome. Cancers (Basel). 2012:4:1180-211

55. Wu G, Feng X, Stein L. Research a human functional protein interaction network and its application to cancer data analysis. Genome Biol. 2010;11:R53.

56. Newman MEJ. Modularity and community structure in networks. Proc Natl Acad Sci. 2006:103:8577-82

57. Assenov Y, Ramírez F, Schelhorn S-E, Lengauer T, Albrecht M. Computing topological parameters of biological networks. Bioinforma. 2008;24(2):282-4.

58. Lê Cao K-A, González I, Déjean S. integrOmics: an R package to unravel relationships between two omics datasets. Bioinformatics. 2009;25:2855-6.

59. Dejean S, Gonzalez I, Lê Cao K-A, Monget P. mixOmics: Omics data integration project, 2011. In: R Packag version. 2011. p. 2-9.

60. Yu JJ, Gaffen SL. Interleukin-17: a novel inflammatory cytokine that bridges innate and adaptive immunity. Front Biosci. 2008;13:170-7.

61. Langrish CL, McKenzie BS, Wilson NJ, de Waal Malefyt R, Kastelein RA, Cua DJ. IL-12 and IL-23: master regulators of innate and adaptive immunity. Immunol Rev. 2004;202:96-105.

62. Le Bon A, Tough DF. Links between innate and adaptive immunity via type I interferon. Curr Opin Immunol. 2002:14:432-6.

63. Pluske JR, Le Dividich J, Verstegen MWA. Weaning the pig: concepts and consequences. Wageningen: Wageningen Academic Pub; 2003.

64. Konstantinov SR, Favier CF, Zhu WY, Williams BA, Kluess J, Souffrant W-B, et al. Microbial diversity studies of the porcine gastrointestinal ecosystem during weaning transition. Anim Res. 2004;53:317-24.

65. Lallès J-P, Bosi $P$, Smidt $H$, Stokes $C R$. Weaning - A challenge to gut physiologists. Livest Sci. 2007;108:82-93.

66. Elahi S, Ertelt JM, Kinder JM, Jiang TT, Zhang $X$, Xin L, et al. Immunosuppressive CD71+ erythroid cells compromise neonatal host defence against infection. Nature. 2013;504:158-62.

67. Belkaid Y, Hand TW. Role of the microbiota in immunity and inflammation. Cell. 2014;157:121-41.

68. Hooper LV, Littman DR, Macpherson AJ. Interactions between the microbiota and the immune system. Science. 2012;336:1268-73.

69. Nicholson JK, Holmes E, Kinross J, Burcelin R, Gibson G, Jia W, et al. Host-gut microbiota metabolic interactions. Science. 2012;336:1262-7.

70. Barabasi A-L, Oltvai ZN. Network biology: understanding the cell's functional organization. Nat Rev Genet. 2004;5:101-13.

71. Albert $\mathrm{R}$, Jeong $\mathrm{H}$, Barabasi A-L. Error and attack tolerance of complex networks. Nature. 2000;406:378-82.

72. Jeong $H$, Mason SP, Barabasi A-L, Oltvai ZN. Lethality and centrality in protein networks. Nature. 2001:411:41-2.

73. Ekman D, Light S, Björklund ÅK, Elofsson A. What properties characterize the hub proteins of the protein-protein interaction network of Saccharomyces cerevisiae? Genome Biol. 2006;7:R45

74. Taylor IW, Linding R, Warde-Farley D, Liu Y, Pesquita C, Faria D, et al. Dynamic modularity in protein interaction networks predicts breast cancer outcome. Nat Biotech. 2009;27:199-204.

75. Levy DE, Darnell JE. STATs: transcriptional control and biological impact. Nat Rev Mol Cell Biol. 2002;3:651-62.

76. Levy DE, Lee C. What does Stat3 do? J Clin Invest. 2002;109:1143-8.

77. Poe SL, Arora M, Oriss TB, Yarlagadda M, Isse K, Khare A, et al. STAT1-regulated lung MDSC-like cells produce IL-10 and efferocytose apoptotic neutrophils with relevance in resolution of bacterial pneumonia. Mucosal Immunol. 2013;6:189-99. 
78. Lad SP, Fukuda EY, Li J, Luis M, Li E. Up-regulation of the JAK/STAT1 signal pathway during Chlamydia trachomatis infection. J Immunol. 2005;174:7186-93.

79. Kernbauer E, Maier V, Stoiber D, Strobl B, Schneckenleithner C, Sexl V, et al. Conditional Stat1 ablation reveals the importance of interferon signaling for immunity to listeria monocytogenes infection. PLoS Pathog. 2012;8, e1002763.

80. Avalle L, Pensa S, Regis G, Novelli F, Poli V. STAT1 and STAT3 in tumorigenesis: a matter of balance. JAK-STAT. 2012;1(2):65-72.

81. Fryknäs M, Dhar S, Öberg F, Rickardson L, Rydåker M, Göransson H, et al. STAT1 signaling is associated with acquired crossresistance to doxorubicin and radiation in myeloma cell lines. Int J Cancer. 2007;120:189-95.

82. Ihle JN. The Stat family in cytokine signaling. Curr Opin Cell Biol. 2001;13:211-7.

83. Qing Y, Stark GR. Alternative activation of STAT1 and STAT3 in response to interferon-gamma. J Biol Chem. 2004;279:41679-85.

84. Konstantinov SR, Awati AA, Williams BA, Miller BG, Jones P, Stokes CR, et al. Post-natal development of the porcine microbiota composition and activities. Environ Microbiol. 2006;8:1191-9.

85. Inoue R, Tsukahara T, Nakanishi N, Ushida K. Development of the intestinal microbiota in the piglet. J Gen Appl Microbiol. 2005;51:257-65.

86. EMEA. Tulathromycin. 2004

87. Jernberg C, Löfmark S, Edlund C, Jansson JK. Long-term impacts of antibiotic exposure on the human intestinal microbiota. Microbiol. 2010;156(11):3216-23.

88. Antonopoulos DA, Huse SM, Morrison HG, Schmidt TM, Sogin ML, Young VB. Reproducible community dynamics of the gastrointestinal microbiota following antibiotic perturbation. Infect Immun. 2009;77(6):2367-75.

89. Ze X, Duncan SH, Louis P, Flint HJ. Ruminococcus bromii is a keystone species for the degradation of resistant starch in the human colon. ISME J. 2012;6:1535-43.

90. Abell GCJ, Cooke CM, Bennett CN, Conlon MA, McOrist AL. Phylotypes related to Ruminococcus bromii are abundant in the large bowel of humans and increase in response to a diet high in resistant starch. FEMS Microbiol Ecol. 2008:66:505-15.

91. Zheng G, Yampara lquise H, Jones JE, Andrew Carson C. Development of Faecalibacterium 16S rRNA gene marker for identification of human faeces. J Appl Microbiol. 2009;106:634-41.

92. Zoetendal EG, Raes J, van den Bogert B, Arumugam M, Booijink CCGM Troost FJ, et al. The human small intestinal microbiota is driven by rapid uptake and conversion of simple carbohydrates. ISME J. 2012;6:1415-26.

93. Wang X, Tao YF, Huang LL, Chen DM, Yin SZ, Ihsan A, et al. Pharmacokinetics of tulathromycin and its metabolite in swine administered with an intravenous bolus injection and a single gavage. J Vet Pharmacol Ther. 2012;35:282-9.

94. Benchaoui HA, Nowakowski M, Sherington J, Rowan TG, Sunderland SJ. Pharmacokinetics and lung tissue concentrations of tulathromycin in swine. J Vet Pharmacol Ther. 2004:27:203-10.

95. Creamer B, Shorter RG, Bamforth J. The turnover and shedding of epithelial cells: part I the turnover in the gastro-intestinal tract. Gut. 1961;2:110-6.

96. Van der Flier LG, Clevers H. Stem cells, self-renewal, and differentiation in the intestinal epithelium. Annu Rev Physiol. 2009;71:241-60.

97. Cox LM, Yamanishi S, Sohn J, Alekseyenko AV, Leung JM, Cho I, et al. Altering the intestinal microbiota during a critical developmental window has lasting metabolic consequences. Cell. 2015;158:705-21.

98. Ahmed R, Gray D. Immunological memory and protective immunity: understanding their relation. Science. 1996;272:54-60.

99. Heinritz SN, Mosenthin R, Weiss E. Use of pigs as a potential model for research into dietary modulation of the human gut microbiota. Nutr Res Rev. 2013;26:191-209.

\section{Submit your next manuscript to BioMed Central and take full advantage of:}

- Convenient online submission

- Thorough peer review

- No space constraints or color figure charges

- Immediate publication on acceptance

- Inclusion in PubMed, CAS, Scopus and Google Scholar

- Research which is freely available for redistribution

Submit your manuscript at www.biomedcentral.com/submit 